Pacific Northwest

National Laboratory

Operated by Battelle for the

U.S. Department of Energy

\title{
Ultrasonic Examination of Double-Shell Tank 241-AN-105 Examination Completed September 2002
}

AF Pardini

GJ Posakony

January 2003

Prepared for the U.S. Department of Energy under Contract DE-AC06-76RL01830 


\title{
DISCLAIMER
}

This report was prepared as an account of work sponsored by an agency of the United States Government. Neither the United States Government nor any agency thereof, nor Battelle Memorial Institute, nor any of their employees, makes any warranty, express or implied, or assumes any legal liability or responsibility for the accuracy, completeness, or usefulness of any information, apparatus, product, or process disclosed, or represents that its use would not infringe privately owned rights. Reference herein to any specific commercial product, process, or service by trade name, trademark, manufacturer, or otherwise does not necessarily constitute or imply its endorsement, recommendation, or favoring by the United States Government or any agency thereof, or Battelle Memorial Institute. The views and opinions of authors expressed herein do not necessarily state or reflect those of the United States Government or any agency thereof.

\author{
PACIFIC NORTHWEST NATIONAL LABORATORY \\ operated by \\ BATTELLE \\ for the \\ UNITED STATES DEPARTMENT OF ENERGY \\ under Contract DE-AC06-76RL01830
}

Printed in the United States of America

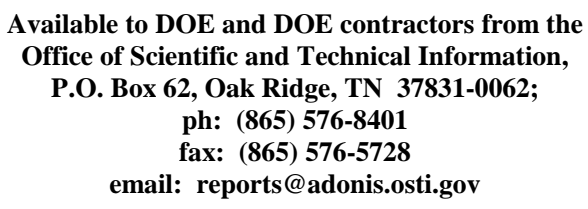

Available to the public from the National Technical Information Service, U.S. Department of Commerce, 5285 Port Royal Rd., Springfield, VA 22161 ph: (800) 553-6847 fax: $(703) 605-6900$

email: orders@ntis.fedworld.gov

online ordering: http://www.ntis.gov/ordering.htm 


\title{
Ultrasonic Examination of D ouble-Shell Tank 241-AN - 105 Examination Completed September 2002
}

\author{
AF Pardini \\ GJ Posakony
}

January 2003

Prepared for

the U.S. D epartment of Energy

under Contract DE-AC06-76RL01830

Pacific Northwest National Laboratory

Richland, Washington 99352 


\section{Summary}

COGEMA Engineering Corporation (COGEMA), under a contract from CH2M Hill Hanford Group (CH2M Hill), has performed an ultrasonic examination of selected portions of Double-Shell Tank 241AN-105. The purpose of this examination was to provide information that could be used to evaluate the integrity of the wall of the primary tank. The requirements for the ultrasonic examination of Tank 241AN-105 were to detect, characterize (identify, size, and locate), and record measurements made of any wall thinning, pitting, or cracks that might be present in the wall of the primary tank. Any measurements that exceed the requirements set forth in the Engineering Task Plan (ETP), RPP-7869, are reported to CH2M Hill and the Pacific Northwest National Laboratory (PNNL) for further evaluation. Under the contract with $\mathrm{CH} 2 \mathrm{M}$ Hill, all data is to be recorded on disk and paper copies of all measurements are provided to PNNL for third-party evaluation. PNNL is responsible for preparing a report(s) that describes the results of the COGEMA ultrasonic examinations.

\section{Examination Results}

The results of the examination of Tank 241-AN-105 have been evaluated by PNNL personnel.

\section{Primary Tank Wall Vertical Scan Paths}

Two 15-in.-wide scan paths were performed on Plate \#1. The plate was examined for wall thinning, pitting, and cracks oriented vertically on the primary tank wall. The results indicated that the minimum thickness in the areas scanned on Plate \#1 was $0.455 \mathrm{in}$., which does not exceed the reportable level of $10 \%$ of the nominal thickness. No vertical crack-like indications were detected in Plate \#1.

Two 15-in.-wide scan paths were performed on Plate \#2. The plate was examined for wall thinning, pitting, and cracks oriented vertically on the primary tank wall. The results indicated three small areas that exceed the minimum thinning reportable level of $10 \%$. However, these three indications (with remaining ligament of 0.422 in., 0.430 in., and 0.435 in.) were analyzed by the UT Level III and were considered pit-like and therefore do not exceed the reportable pitting level of $25 \%$ of the nominal thickness. No vertical crack-like indications were detected in Plate \#2.

\section{Primary Tank Wall Horizontal Scan Paths}

Three 15-in.-wide scan paths were performed on Plate \#2. The plate was examined for wall thinning, pitting, and cracks oriented circumferentially on the primary tank wall. The results indicated five small areas that exceed the minimum thinning reportable level of $10 \%$. However, these five indications (with remaining ligament of 0.425 in., 0.427 in., 0.448 in., 0.444 in., and 0.423 in.) were analyzed by the UT Level III and were considered pit-like and therefore do not exceed the pitting reportable level of $25 \%$ of the nominal thickness. No circumferential crack-like indications were detected in Plate $\# 2$. 


\section{Contents}

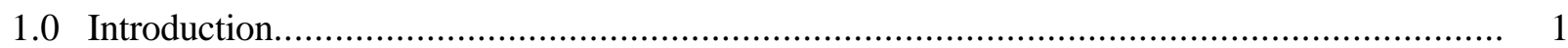

2.0 Qualified Personnel, Procedures, and Equipment ................................................... 2

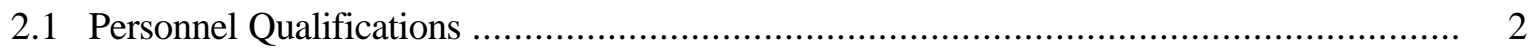

2.2 Ultrasonic Examination Equipment ............................................................... 3

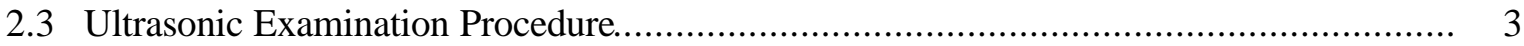

3.0 Ultrasonic Examination Configuration ................................................................ 4

4.0 Ultrasonic Examination Location..................................................................... 5

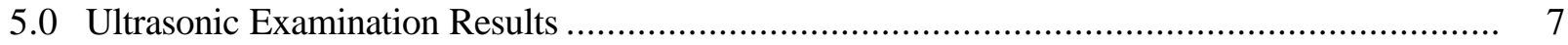

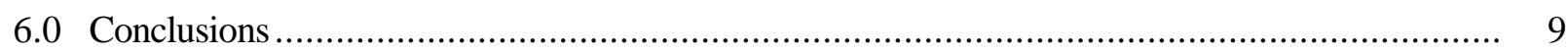

6.1 Primary Tank Wall Vertical Scan Paths .............................................................. 9

6.2 Primary Tank Wall Horizontal Scan Paths........................................................... 9 


\section{Figures}

3.1 Transducer Configuration for Examining the Primary Tank Wall ................................. 4

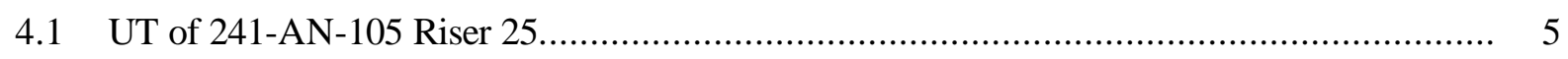

4.2 Sketch of Vertical and Circumferential Scan Paths on Tank 241-AN-105...................... 6

5.1 UT Data from Tank 241-AN-105 ..................................................................... 8 


\subsection{Introduction}

COGEMA Engineering Corporation (COGEMA), under a contract from CH2M Hill Hanford Group (CH2M Hill), has performed an ultrasonic examination (UT) of selected portions of Double-Shell Tank (DST) 241-AN-105. The purpose of this examination was to provide information that could be used to evaluate the integrity of the DST. The requirements for the UT of Tank 241-AN-105 were to detect, characterize (identify, size, and locate), and record measurements made of any wall thinning, pitting, or cracks that might be present in the wall of the primary tank. Any measurements that exceed the requirements set forth in the Engineering Task Plan (ETP), RPP-7869, are reported to CH2M Hill and the Pacific Northwest National Laboratory (PNNL) for further evaluation. Specific measurements that are reported include the following:

- Wall thinning that exceeds $10 \%$ of the nominal thickness of the plate.

- Pits with depths that exceed $25 \%$ of the nominal plate thickness.

- Stress-corrosion cracks that exceed 0.10 in. (through-wall) that are detected in the inner wall of the tank, HAZ of welds, or in the tank knuckle.

The accuracy requirements for ultrasonic measurements for the different types of defects are as follows:

- Wall thinning - measure thickness within \pm 0.020 in.

- Pits - size depths within \pm 0.050 in.

- Cracks - size the depth of cracks on the inner wall surfaces within \pm 0.1 in.

- Location - locate all reportable indications within \pm 1.0 in.

Under the contract with $\mathrm{CH} 2 \mathrm{M}$ Hill, all data is to be recorded on disk and paper copies of all measurements are provided to PNNL for third-party evaluation. PNNL is responsible for preparing a report(s) that describes the results of the COGEMA UT. 


\subsection{Qualified Personnel, Procedures, and Equipment}

Under contract from $\mathrm{CH} 2 \mathrm{M}$ Hill, qualification of personnel participating in the DST inspection program, the UT equipment (instrument and mechanical scanning fixture), and the UT procedure that will be used in the examination of the current DST is required. Personnel participating in the examinations are to be certified in accordance with American Society for Nondestructive Testing (ASNT) Guideline SNTTC-1A-92 and associated documentation is to be provided. The capability of the UT system is to be validated through a performance demonstration test (PDT) on a mock-up simulating the actual DST. The current procedure for the UT is to be based on the Section V, Article 4, Boiler and Pressure Vessel Code defined by the American Society for Mechanical Engineers (ASME).

\subsection{Personnel Qualifications}

The following individuals were qualified and certified to perform UT of the Hanford DST 241AN-105:

- Mr. Wesley Nelson, ASNT Level III in UT, has been identified as COGEMA’s UT Level III authority for this project. Mr. Nelson has been certified by COGEMA as a UT Level III in accordance with COGEMA procedure COGEMA-SVCP-PRC-014, latest revision. Further documentation has been provided to establish his qualifications. Reference: Letter from PNNL to C.E. Jensen dated August 22, 2000, "Report on Performance Demonstration Test - PDT, May 2000."

- Mr. James B. EIder, ASNT Level III in UT, has been contracted by COGEMA to provide peer review of all DST UT data. Mr. Elder has been certified by JBNDT as a UT Level III in accordance with JBNDT written practice JBNDT-WP-1, latest revision. Further documentation has been provided to establish his qualifications. Reference: PNNL-11971, Final Report - Ultrasonic Examination of Double-Shell Tank 241-AN-107.

- Mr. William D. Purdy, COGEMA UT Level II limited (for P-Scan data acquisition only). Mr. Purdy has been certified in accordance with COGEMA procedure COGEMA-SVCP-PRC-014, latest revision. Further documentation has been provided to establish his qualifications. Reference: Letter from PNNL to C.E. Jensen dated October 5, 2001, "Purdy Performance Demonstration Test (PDT) Report."

- Mr. Jon D. Elliott, COGEMA contracted UT Level II limited (for P-Scan data acquisition only). Mr. Elliott has been contracted by COGEMA (CH2M Hill employee) and has been certified in accordance with COGEMA procedure COGEMA-SVCP-PRC-014, latest revision. Further documentation has been provided to establish his qualifications. Reference: Letter report TWS02.044 from PNNL to C.E. Jensen dated July 2, 2002, “Jon D. Elliott Performance Demonstration Test Report." 


\subsection{Ultrasonic Examination Equipment}

CH2M Hill has provided the UT equipment for the examination of Tank 241-AN-105. This equipment consists of a Force Institute P-Scan ultrasonic test instrument and a Force Institute AWS-5D remote-controlled, magnetic-wheel crawler for examining the primary tank wall. Ultrasonic transducers used for the examinations are commercial off the shelf. The P-Scan ultrasonic system has been qualified through a PDT. Reference: PNNL-11971, Final Report- Ultrasonic Examination of Double-Shell Tank 241-AN-107.

\subsection{Ultrasonic Examination Procedure}

COGEMA has provided the UT procedure for the examination of Tank 241-AN-105. This procedure, COGEMA-SVUT-INS-007.3, Revision 1, outlines the type of UT and mechanical equipment that are to be used as well as the types of transducers. Both straight-beam and angle-beam transducers are used for the examination of the primary tank wall. The examination procedures include full documentation on methods for calibration, examination, and reporting. Hard copies of the T-Scan (thickness) and P-Scan (projection or angle beam) views of all areas scanned are made available for analysis. The UT procedure requires the use of specific UT transducers for the different examinations. A calibration performed before and after the examinations identifie s the specific transducers used and the sensitivity adjustments needed to perform the inspection. The COGEMA UT procedure has been qualified through a Performance Demonstration Test. Reference: PNNL-11971, Final Report - Ultrasonic Examination of Double-Shell Tank 241-AN-107. 


\title{
3.0 Ultrasonic Examination Configuration
}

COGEMA is required to inspect selected portions of the DSTs which may include the primary and secondary tank walls, the heat-affected zones of primary tank vertical and horizontal welds, and the tank knuckle and bottoms. The P-Scan system has been configured to perform these examinations and has been performance tested. The examination of Tank 241-AN-105 only included UT of the primary tank wall. Figure 3.1 provides details on the actual configuration for the examination of the primary tank wall, and also provides an example of the scanning configuration generally used during an examination of the primary tank wall. However, other configurations can be used at the discretion of the COGEMA Ultrasonic Level III (i.e., 45-degree transducers can be removed for simple wall thickness measurements).

The functional diagram in Figure 3.1 shows one straight-beam and two angle-beam transducers ganged together for examining the primary tank wall. The straight beam is designed to detect and record wall thinning and pits, and the angle beams are designed to detect and record any cracking that may be present. These transducers are attached to the scanning bridge and they all move together. Information is captured every $0.035 \mathrm{in}$. (or as set by the NDE inspector) as the assembly is scanned across a line. At the end of each scan the fixture is indexed 0.035 in. (or as set by the NDE inspector) and the scan is repeated. The mechanical scanning fixture is designed to scan a maximum of $15 \mathrm{in}$. and then index for the next scan. The hard copy provides a permanent record that is used for the subsequent analysis.

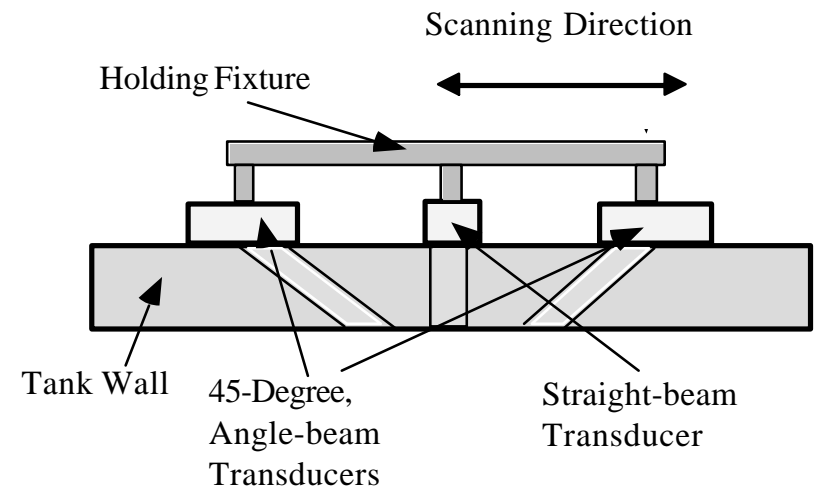

\author{
Transducer Specifications: \\ Angle-beam \\ Type: MWB-45 04E \\ Frequency : $4 \mathrm{MHz}$ \\ Size: 8 X $9 \mathrm{~mm}$. \\ Manufacturer: Krautkramer \\ Straight-beam \\ Type: MSEB 5B \\ Frequency: $5 \mathrm{MHz}$ \\ Size: Dual - 8 X $2 \mathrm{~mm}$ \\ Manufacturer: Krautkramer
}

Figure 3.1. Transducer Configuration for Examining the Primary Tank Wall 


\subsection{Ultrasonic Examination Location}

Tank 241-AN-105 is located in the Hanford 200 East area in AN Tank Farm. The crawler and associated scanner were lowered into the 24-in. riser located on the south side of 241-AN-105 and designated as Riser 25. In the previous examination of 241-AN-105 in 1999, the examination took place in Riser 6B. Riser 6B has been renamed Riser 25. Figure 4.1 provides a graphic of the location of this riser.

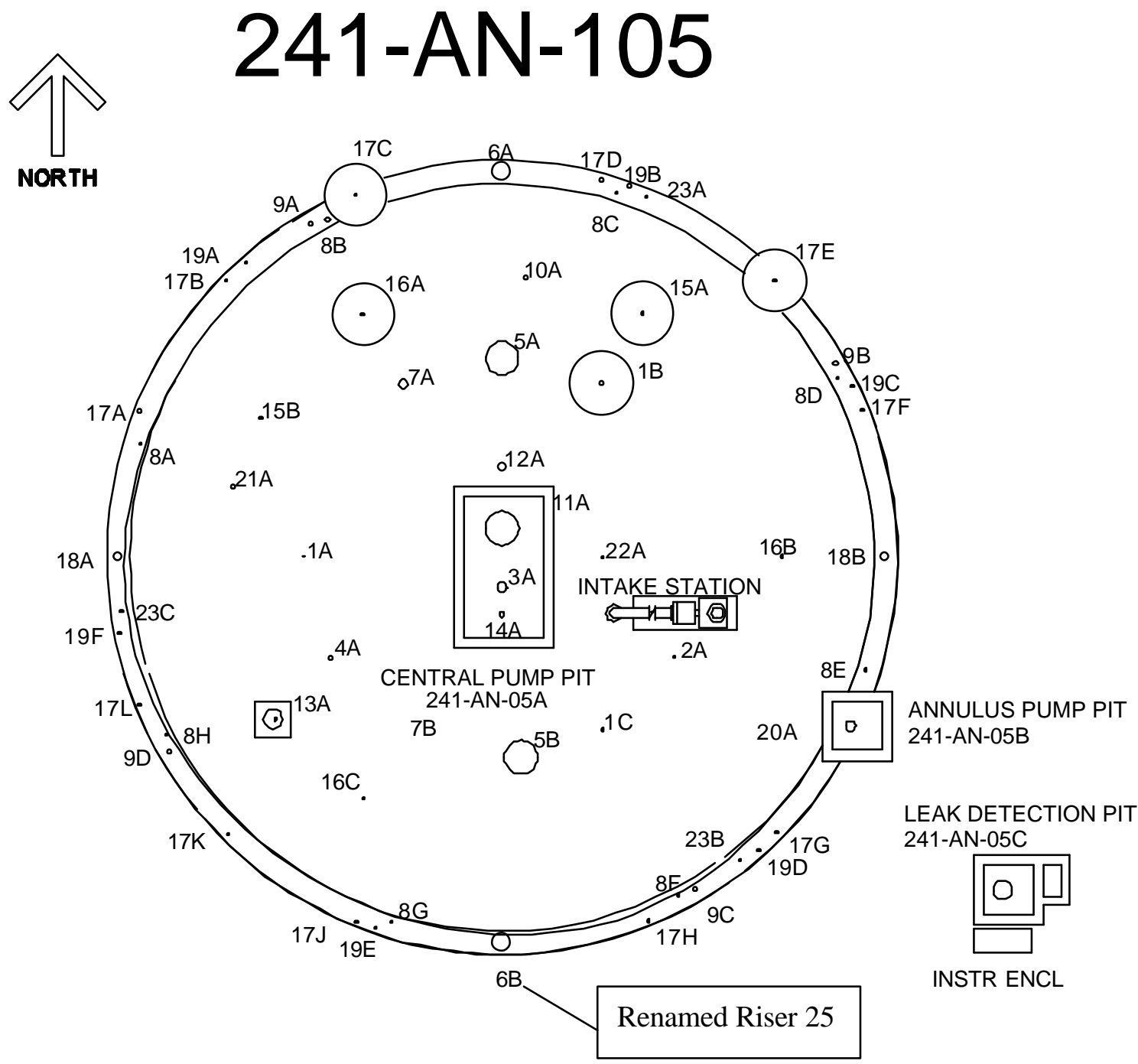

Figure 4.1. UT of 241-AN-105 Riser 25 
Figure 4.2 describes the areas on the primary wall of Tank 241-AN-105 that were ultrasonically examined. Two 15-in.-wide vertical scan paths were performed on Plates \#1 and \#2 below the entrance to Riser 25. Three additional horizontal scan paths were performed near the lower section of plate \#2.

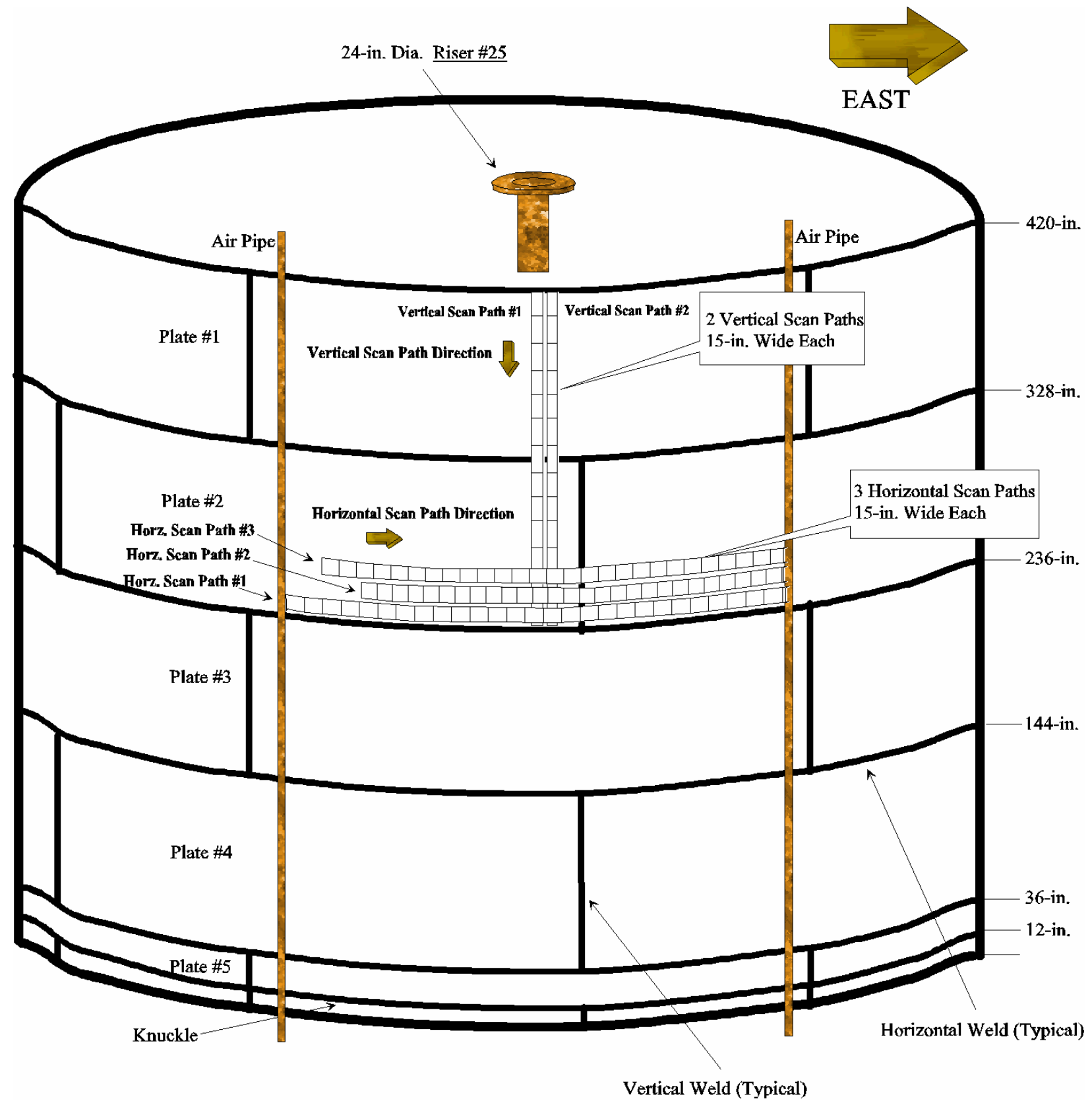

Figure 4.2. Sketch of Vertical and Circumferential Scan Paths on Tank 241-AN-105 


\subsection{Ultrasonic Examination Results}

COGEMA has provided detailed reports including T-Scan and P-Scan hard copies of all areas that were ultrasonically examined to PNNL for third-party review. The data was analyzed by COGEMA Level III Mr. Wes Nelson and peer reviewed by JBNDT Level III Mr. Jim Elder. The results of the examination of Tank 241-AN-105 are presented in Figure 5.1.

Figure 5.1 shows that the examination consisted of two vertical and three horizontal scan paths beneath the 24-in. diameter riser. Vertical scan \#1 was 15-in. wide on Plates \#1 and \#2 and was directly below the 24-in riser. Vertical scan \#2 was adjacent to vertical scan \#1 and was also 15-in. wide on Plates \#1 and \#2. Three horizontal scan paths, 15-in. wide, were completed on the lower section of Plate \#2 and basically extended between the two vertical air pipes. Due to poor visibility with the camera overview, the starting points of each of the three scan paths were different. Areas that show two measurements are the result of the vertical scan paths overlapping the horizontal scan paths. Figure 5.1 displays the minimum reading taken in each 15 -in. wide by 12 -in. long portion of the scan. In the overlapping areas, both minimum readings from each of vertical and horizontal scan paths are given.

Pit-like indications were observed in the shaded areas of Figure 5.1. There were eight pit-like indications that exceeded the $10 \%$ wall thinning criteria. However, none of these pit-like indications exceeded the pitting criteria of $25 \%$ of nominal plate thickness and are therefore not reportable.

Examination for cracks oriented vertically was performed during the two vertical scan paths in Plates \#1 and \#2. No vertical crack-like indications were noted.

Examination for cracks oriented circumferentially was performed during the three horizontal scan paths in Plate \#2. No circumferential crack-like indications were noted. 


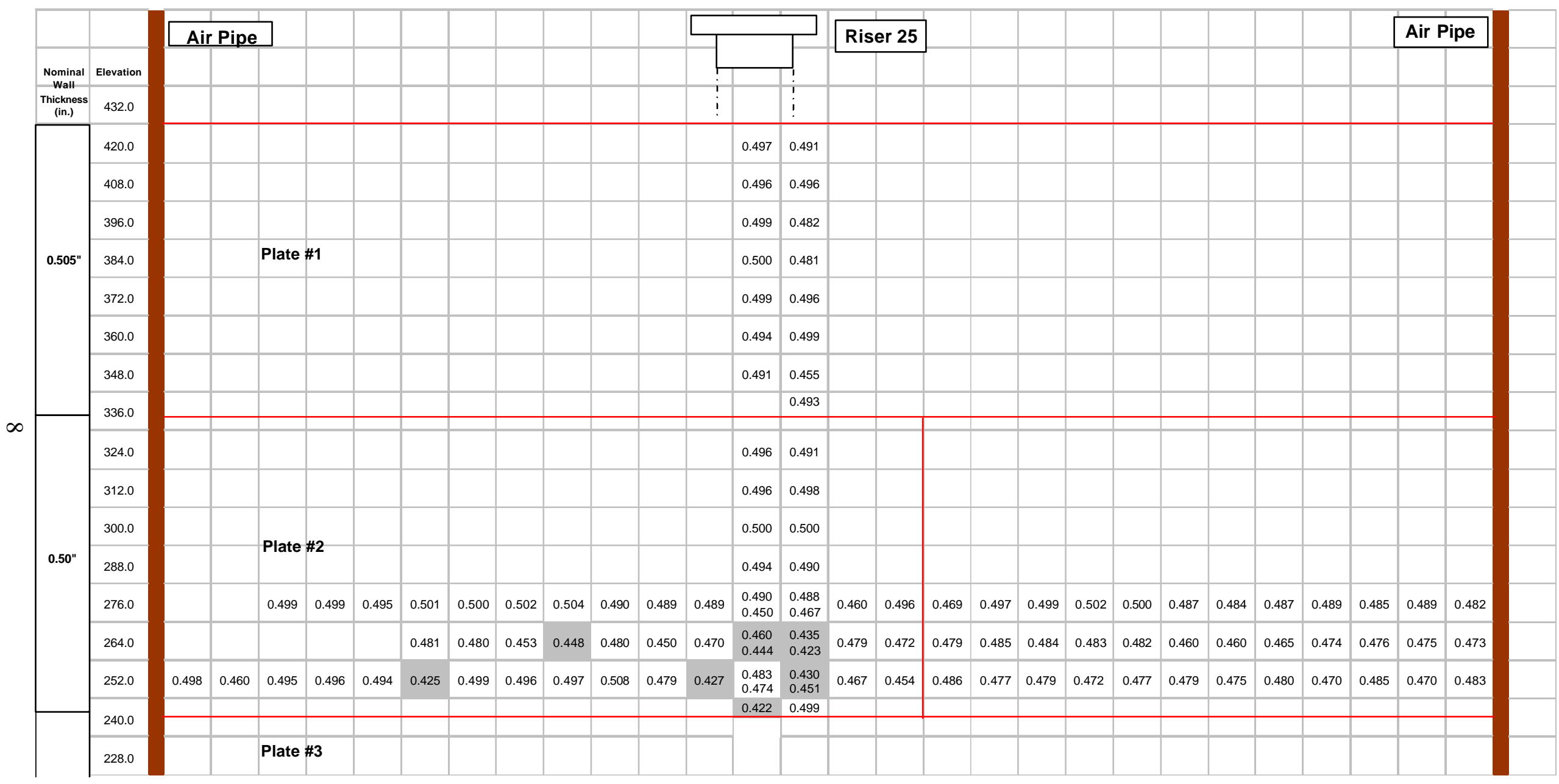

Figure 5.1. UT Data from Tank 241-AN-105 


\subsection{Conclusions}

The results of the examination of Tank 241-AN-105 have been evaluated by PNNL personnel. The UT showed minimal corrosion. The examination focused on Plates \#1 and \#2 and did not include an examination of the heat-affected zones of any weld.

\subsection{Primary Tank Wall Vertical Scan Paths}

Two 15-in.-wide scan paths were performed on Plate \#1. The plate was examined for wall thinning, pitting, and cracks oriented vertically on the primary tank wall. The results indicated that the minimum thickness in the areas scanned on Plate \#1 was 0.455 in., which is does not exceed the reportable level of $10 \%$ of the nominal thickness. No vertical crack-like indications were detected in Pla te \#1.

Two 15-in.-wide scan paths were performed on Plate \#2. The plate was examined for wall thinning, pitting, and cracks oriented vertically on the primary tank wall. The results indicated three small areas that exceed the minimum thinning reportable level of $10 \%$. However, these three indications (with remaining ligament of 0.422 in., 0.430 in., and 0.435 in.) were analyzed by the UT Level III and were considered pit-like and therefore do not exceed the pitting reportable level of $25 \%$ of the nominal thickness. No vertical crack-like indications were detected in Plate \#2.

\subsection{Primary Tank Wall Horizontal Scan Paths}

Three 15-in.-wide scan paths were performed on Plate \#2. The plate was examined for wall thinning, pitting, and cracks oriented circumferentially on the primary tank wall. The results indicated five small areas that exceed the minimum thinning reportable level of $10 \%$. However, these five indications (with remaining ligament of 0.425 in., 0.427 in., 0.448 in., 0.444 in., and 0.423 in.) were analyzed by the UT Level III and were considered pit-like and therefore do not exceed the pitting reportable level of $25 \%$ of the nominal thickness. No circumferential crack-like indications were detected in Plate \#2. 


\section{Distribution}

No. of

Copies

Offsite

4 DOE/Office of Scientific and

Technical Information \&

Information Release

1 DOE Office of Science and

Technology

Kurt Gerdes

1154 Cloverleaf Building

19901 Germantown Road

Germantown, MD 20874-1290

\section{Onsite}

\section{Hanford Site}
J. L. Castleberry (1)
R3-76
G. P. Duncan (1)
R3-76
C. E. Jensen (2)
R3-76

10 Pacific Northwest National Laboratory

M. T. Anderson (1)

K5-26

J. W. Brothers (1)

$\mathrm{K} 7-15$

L. O. Casazza (1)

K5-26

A. F. Pardini (6)

K5-26

G. J. Posakony (1)

K5-26 